PUC-Rio

Rio de Janeiro, Abril de 2008

Dissertação por Carlos Antonio Pittella de Souza Leite

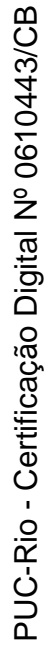

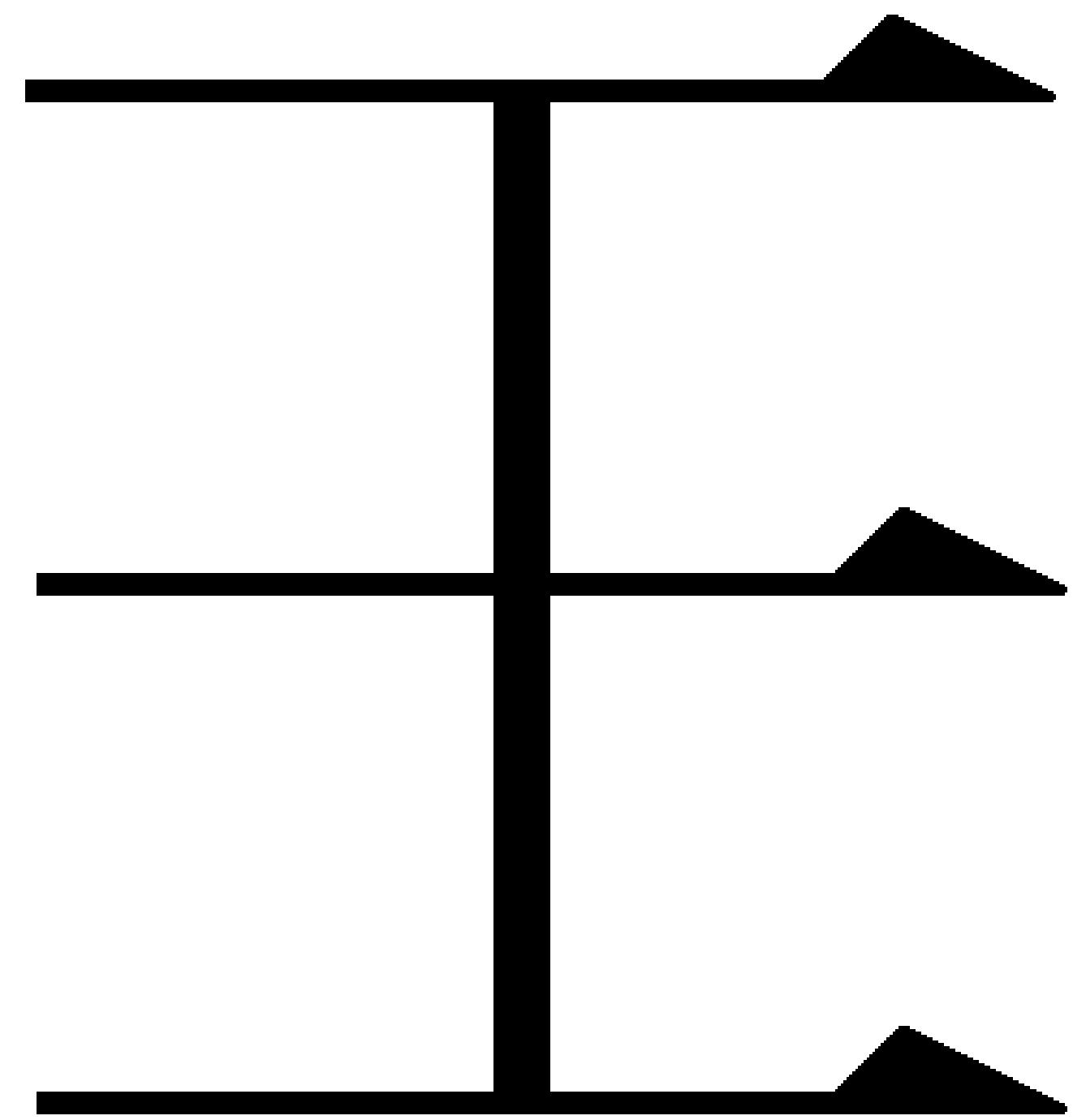




\section{RESUMO POÉTICO}

ou

uma tradução do ideograma chinês que é título e já resumo deste trabalho, logo um resumo de palavras para tentar explicar o resumo do ideograma, um resumo muito maior para tentar entender o resumo menor em extensão que na verdade é o maior em densidade, porque um resumo se mede como uma semente:

pelo seu poder de semear, verbo da raiz latina "seme" irmão talvez da sânscrita "sama" (junto, denso) primo quiçá da semente-junta grega "sema" que frutificou signos como "Semiótica", a árvore cultivada por Charles Sanders Peirce, uma Lógica dos Signos ou do Semear, pois os signos são sementes e tudo é signo em potência-densa

como o ideograma-título-resumo deste trabalho que pode ao mesmo tempo conter e gerar toda a Semiótica para nossa admiração

de seu movimento triádico (mais que dual) de crescimento pois para crescer é preciso mais que dois traços, pois dois só provam e reprovam o contrário do erro do outro... numa dialética monótona,

daí precisarmos de um terceiro ramo ao meio para servir de ponte entre os extremos que, assim, já podem andar em equilíbrio mesmo se precisarem estudar o desconhecido, pois o meio (vão-central da Semiótica) sempre se pode mover em Semiose, o crescimento geral expresso pelo traço vertical, o tronco

que resume a conexão dos três num só significando, em chinês, "Governar" ou "ligar o céu, a terra e o homem", pois governar significa na realidade servir, servir de ponte-signo-semente para crescer em vez de transgredir pois o crescimento é que é a lei,

o governo único de abrir-se que não se pode transgredir, pois transgredir mesmo seria só fechar com medo das ameaçadoras exceções que só se explicariam no re-conhecimento dos erros como sementes-possibilidades, ao que traduzimos o ideograma, por fim (e o fim da semente é só o início da árvore) como

\section{Gramática da União}

como ensina Fernando Pessoa:

- Toda vida existe por virtude de um equilíbrio. 


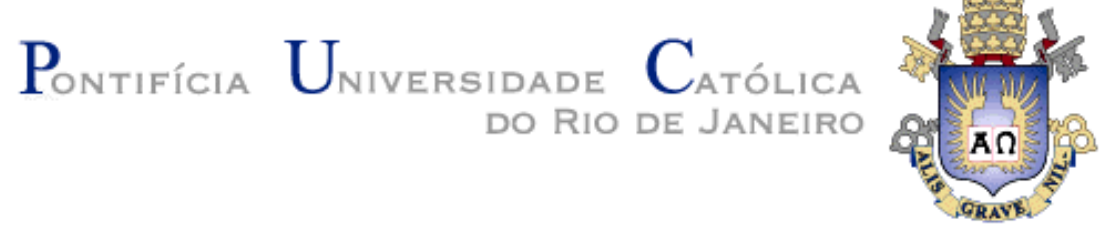

Carlos Antonio Pittella de Souza Leite

Gramática da União em Fernando Pessoa

Dissertação de Mestrado

Dissertação apresentada ao Programa de Pós-graduação em Letras da PUC-Rio como requisito parcial para obtenção do grau de Mestre em Letras.

Orientador: Prof. Cleonice Serôa da Motta Berardinelli

Rio de Janeiro,

Abril de 2008 
Carlos Antonio Pittella de Souza Leite

\title{
Gramática da União em Fernando Pessoa
}

\section{Dissertação de Mestrado}

Dissertação apresentada ao Programa de Pós-graduação em LHtraV da PUC-Rio como requisito IISDURDOISDU obtenção do grau de Mestre em Letras. Aprovada pela Comissão Examinadora abaixo-DMQQDGD] ]

\author{
Prof. Cleonice Serôa da Motta Berardinelli \\ Orientadora \\ Departamento de Letras - PUC-Rio
}

Prof. Helena Franco Martins Co-orientadora Departamento de Letras - PUC-Rio

Prof. Karl Erik Schøllhammer Departamento de Letras - PUC-Rio

Prof. Maurício Matos Departamento de Letras Vernáculas - UFRJ

Prof. Paulo Fernando Carneiro de Andrade Coordenador Setorial do Centro de Teologia e Ciências Humanas - PUC-Rio 
Todos os Direitos Reservados. É Proibida reprodução total ou parcial do trabalho sem autorização da universidade, do autor, e da orientadora.

\section{Carlos Antonio Pittella de Souza Leite (Carlos Pittella)}

Graduou-se em Jornalismo pela PUC-Rio em 2005. No mesmo ano, publicou em Coimbra o livro civilizações volume dois (Palimage Editores), incluindo o poema "Árvore das Palavras", premiado pela Universidade de Coimbra. Em 2006, recebeu menção honrosa no $1^{\circ}$ Prêmio de Poesia UBE/Scortecci, pelo livro dissonetos para eu-lírio. Desde 2006, preside a ONG de Educação Ecológica União das Árvores, pela qual organiza o projeto Ecopoesia, promovendo aulas de Português $\&$ Literatura de maneira transdisciplinar. Tem no prelo o livro Todos pela Ponte, sobre Semiótica \& Literatura, área em que pesquisa, enveredando ainda pelas gramáticas orientais, nomeadamente de Pânini e Patâñali.

Ficha Catalográfica

Pittella, Carlos

Gramática da União em Fernando Pessoa / Carlos Pittella ; orientadora: Cleonice Serôa da Motta Berardinelli ; co-orientadora: Helena Franco Martins. - 2008.

170 f. : il. ; $30 \mathrm{~cm}$

Dissertação (Mestrado em Letras)-Pontifícia Universidade Católica do Rio de Janeiro, Rio de Janeiro, 2008.

Inclui bibliografia

1. Letras - Teses. 2. Pessoa, Fernando. 3. Gramática. 4. Tradição \& anti-tradição. 5. Semiótica peirciana. 6. Patâñjali. I. Berardinelli, Cleonice Serôa da Motta. II. Martins, Helena Franco. III. Pontifícia Universidade Católica do Rio de Janeiro. Departamento de Letras. IV. Título. 
para Lucia que ama Charles, para Cléo que ama Fernando

para Ani que me ama, pequenino neste meio;

para os pais que amam em ponto.

.... União que ama crescendo...

e Paramahansa Yogananda que ama sem tamanho 


\section{Agradecimentos}

Devo graças a Deus por tudo, que é Divino e Maravilhoso.

A minha mãe, Ana, por levar a sério quando eu escrevia uma História do Mundo, pouco depois de eu ter aprendido a escrever.

Ao meu pai, Antônio, por pôr Supertramp para a barriga de minha mãe ouvir.

Ao meu irmão, Pedro, por me ensinar a "curtir".

A Christian Toth, por estar sorrindo e lendo Dom Quixote, no meio da aula de filosofia em que pensei em desistir.

A todos os jardineiros, semeadores e servos da União das Árvores, pela confiança.

À Professora Cleonice, por nos fazer sentir com a mesma idade ao conversarmos.

À Professora Helena Martins, por confiar num barco andando, segundo a Lógica da Errância de Peirce e com instruções em Sânscrito!

Ao Professor Karl Erik, pela seriedade justamente equilibrada com disponibilidade.

Ao Professor Maurício Matos, pela contagiante dedicação com que pesquisa.

Ao Professor Alexandre Montaury, por ouvir, mesmo quando falei que "Daniel Faria” era o melhor poeta português depois de Fernando Pessoa.

À Professora Eneida Bomtempo, por usar o vocativo "cara" ao lidar comigo.

À Professora Graça Capinha, por me obrigar a publicar um livro em Coimbra (e por resgatar-me do centro de uma roda de 30 capas pretas embriagadas).

À Professora Lucia Santaella, por estudar os 80 mil manuscritos de Peirce.

Ao Professor Rogério Duarte, por levar a vida como um sonho de Deus.

À Professora Izabel Margato, por sorrir na entrevista de seleção do Mestrado, quando eu pensava ter sido reprovado sumariamente.

A Aniele Xavier, por acompanhar e respeitar, mesmo que às vezes sem entender.

A Stephanie Wilks, por acreditar que a Paz é possível e que vale a pena buscá-la.

A Luciana Gattas, sem a qual este texto jamais seria formatado a tempo.

A cada um dos 72 Fernando-Pessoas no drama em Poesia em busca da Verdade. 


\section{Resumo}

Pittella, Carlos; Berardinelli, Cleonice Serôa da Mota Berardinelli (Orientadora); Martins, Helena Franco (Co-orientadora). Gramática da União em Fernando Pessoa. Rio de Janeiro, 2008. 170p. Dissertação de Mestrado - Departamento de Letras, Pontifícia Universidade Católica do Rio de Janeiro.

"Que coisa morro quando sou?", diz Fernando Pessoa, cometendo um certíssimo "erro" de Português, apesar de (ou justamente por) dominar os recursos gramaticais da Língua Portuguesa. Como entender as "errâncias gramaticais" de Pessoa, visto que fazem perfeito sentido em sua obra? E, se fazem sentido, que Gramática tais "erros" seguem ou criam que não a tradicional? Interessa-nos compreender como comparece no campo específico da linguagem pessoana a delicada economia entre tradição e anti-tradição - como se dá a relação entre "as forças necessárias" do uso e $a b$-uso da Linguagem, com ênfase no exame da aptidão pessoana para superar aporias inerentes ao pensamento dualista. Nossa Hipótese é que a linguagem de Pessoa aponta para uma Gramática que, em vários sentidos, cultiva o signo da União: a) entre erro \& norma gramatical ou, em sentido mais amplo, entre tradição \& anti-tradição; b) entre diversas ciências ou áreas do conhecimento, fundidas nas grandes sínteses que os heterônimos encarnam e comunicáveis por uma lógica afim à Semiótica proposta pelo pensador Charles Sanders Peirce;

c) entre as diversas perspectivas poéticas pessoanas perseguindo uma mesma "febre de Além".

\section{Palavras-chave}

Pessoa, Fernando; Gramática; Tradição \& anti-tradição; Semiótica peirciana; Patâñali. 


\section{Abstract}

Pittella, Carlos; Berardinelli, Cleonice Serôa da Mota Berardinelli (Advisor); Martins, Helena Franco (Co-advisor). Grammar of Union in Fernando Pessoa. Rio de Janeiro, 2008. 170p. MSc. Dissertation Departamento de Letras, Pontifícia Universidade Católica do Rio de Janeiro.

"What thing die I, when I am?" (sic), says Fernando Pessoa, committing a correct Grammatical "mistake", in spite (or exactly because) of dominating the resources of his Language. How to understand Pessoa's "grammar errancies", since they make perfect sense in his work? And, if they make sense, what Grammar these "errancies" follow or create that is not the traditional one? It interests us to understanding how does work in the specific field of Pessoanean language the delicate economy between tradition and anti-tradition - how does occur the relation between "the necessary forces" of use and $a b$-use of Language, emphasizing Pessoa's aptitude to overcome the aporias inherent to the dualistic thought. Our Hypothesis is that Pessoa's Language points to a Grammar that, in several senses, cultivates the sign of Union: a) between error \& grammatical norm or, in wider sense, between tradition \& anti-tradition; b) among different sciences or fields of knowledge, melted by the great synthesis that the heteronyms embody, and being communicable through a Logics kindred to the Semiotics proposed by the thinker Charles Sanders Peirce; c) among the diverse Pessoanean poeticperspectives chasing the same "fever of Beyond".

\section{Keywords}

Pessoa, Fernando; Grammar; Tradition \& anti-tradition; Peircean's Semiotics; Patânjali. 


\section{Sumário}

$\begin{array}{ll}\text { Introdução } & 15\end{array}$

i) Nota Preliminar $\quad 15$

ii) Confissão Triádica 16

iii) O Objeto - de Pessoa 17

iv) A Tese - de Patânjali 23

v) A Metodologia - de Peirce 27

Sūtra 0 = Gramática da União 30

1. Estilística como Estética 33

1.1. SENTIDO 39

1.1.1. Silêncio 42

1.1.2. Som 47

1.1.3. Linguagem $\quad 51$

1.2. FIGURAS 57

1.2.1. Metáfora $\quad 61$

1.2.2. Metonímia 68

1.2.3. Pleonasmo 75

1.3. SISTEMA 83

1.3.1. Paradoxo 86

1.3.2. Antítese $\quad 89$

1.3.3. Contradição 92 
2. Sintaxe como Ética 97

2.1. REGÊNCIA 106

2.1.1. Potência 108

2.1.2. Polarização 112

2.1.3. Gravitação $\quad 115$

2.2. FUNÇÕES 119

2.2.1. Semente $\quad 121$

$\begin{array}{ll}\text { 2.2.2. Hera } & 124\end{array}$

$\begin{array}{ll}\text { 2.2.3. Abelha } & 127\end{array}$

2.3. CONCORDÂNCIA 130

2.3.1. Idealogia 132

2.3.2. Nonsense 135

2.3.3. Normalidade 138

3. Esboço de uma Semântica como Semiótica 142

4. Considerações Finais-Re-Iniciais 152

$\begin{array}{ll}\text { Referências Bibliográficas } & 153\end{array}$

ANEXO: Tabela de Chaves de Análise 161 


\section{Índice de ilustrações}

Figura 01 - Triângulo Pessoa-Peirce-Patâñjali 16

Figura 02 - Sūtra I:42 de Patâñjali 23

Figura 03 - Arquitetura das Ciências de Peirce 31

Figura 04 - Fórmula da Palitoxina 33

Figura 05 - Mapa da Estilística como Estética 34

Figura 06 - Os 1001 primeiros algarismos do п (pi) 40

Figura 07 - As 3 vogais primordiais, segundo o Sânscrito $\quad 49$

Figura 08 - Fonética dos Deuses 49

Figura 09 - Organismo / Caos = Mensagem / Ruído 53

Figura 10 - Diagrama da Semiose 54

Figura 11 - Ypsilon como signo triádico 55

Figura 12 - Ideograma "Governar"

Figura 13 - Diagrama de Venn para o Ícone 61

Figura 14 - Universo da Linguagem (vol. I) 63

Figura 15 - "Silêncio", poema concreto de Eugen Gomringer 66

Figura 16 - Equações Ideogramáticas de Serguéi Eisenstein 71

Figura 17 - Obra "Drawing Hands", de M. C. Escher 74

Figura 18 - Desafio de Leitura com Citação Pessoana 78

Figura 19 - Proporções de Colderidge 78

Figura 20 - Diagrama de Aristóteles Poética-Retórica-Lógica 79

Figura 21 - Diagrama das Sementes Englobantes 79

Figura 22 - Os 3 Eixos da Linguagem, d'après Jakobson 82

Figura 23 - Quadrinhos: O Machismo segundo Cebolinha 91

Figura 24 - Os 3 Planos para o Universo 93

Figura 25 - Painel 25 do Profeta Gentileza 97

Figura 26 - Mapa da Sintaxe como Ética 98

Figura 27 - Sūtra Il:30 de Patâñjali $\quad 99$

Figura 28 - Universos da Linguagem (vol. II) 104

Figura 29 - Três Tricotomias de Signos Peirceanos 106 
Figura 30 - Equação de Einstein para a Relatividade 110

Figura 31 - Equação de Newton para a Lei da Gravidade 116

Figura 32 - Descolamentos de Regência por Perini 117

Figura 33 - Curvatura do Espaço-Tempo segundo Einstein 118

Figura 34 - Partitura de Análise Sintática de José Oiticica 119

Figura 35 - Clipart das Setas na Encruzilhada 119

Figura 36 - Desenho Semente-Hera-Abelha 120

Figura 37 - Anatomia do Átomo 121

Figura 38 - Resultante do Choque de 2 núcleos de Ouro 124

Figura 39 - Ideograma para "Leste" = Sol + Árvore 126

Figura 40 - Equação Ideogramática para "Vermelho" 126

Figura 41 - O "Muro" segundo Arthur Bispo do Rosário 128

Figura 42 - Poema de Arthur Bispo do Rosário 132

Figura 43 - Pintura da Mulher-Esfinge de Francis Bacon 136

Figura 44 - "Menina toma remédio" 139

Figura 45 - O DNA de uma Mosca 142

Figura 46 - Esboço do mapa da Semântica 143

Figura 47 - Sūtra I:27 de Patâñjali 144

Figura 48 - Prañava / AUM = Verbo / Amém 144

Figura 49 - Sūtras para uma Semântica Semiótica $\quad 151$ 
Ultrapassar sem tropeçar...

(Angel Vianna,

educadora-bailarina)

Que tenha como parte de sua tradição o rompimento.

(Nilton Bonder,

escritor-rabino)

Que coisa morro quando sou?

(Fernando Pessoa,

cristão-pagão) 